\title{
Making online learning accessible to disabled students: an institutional case study
}

\author{
Martyn Cooper*
}

Open University, UK

\begin{abstract}
Based on the authors' reflections on experience working at the Open University, approaches to making online learning accessible to disabled students are considered. The considerations are applicable to all concerned with online learning and indeed anyone seeking to trade, disseminate information and mediate services online. In reflecting on the Open University experience of making online material accessible, pedagogic, organisational and cultural issues are highlighted and it is argued that it is important to address these issues in order to effect the organisational change needed to ensure that accessibility challenges are effectively met.
\end{abstract}

\section{Introduction}

In order to provide a context for the author's reflections on the Open University (OU) experience of making online material accessible, three key areas will be introduced:

- The accessibility context: what is accessibility and why it is important?

- The UK legislative context.

- The Open University context.

The accessibility context: what is accessibility and why is it important?

Accessibility is a term that has particular meanings in different contexts; here it refers to design qualities that endeavour to make online learning available to all by ensuring that the way it is implemented does not create unnecessary barriers however the student may interact with their computer. Virtually anyone, irrespective of any disability, can be enabled to interact effectively with a computer. Some people with

\footnotetext{
*Institute of Educational Technology (IET), Walton Hall, Milton Keynes MK7 6AA, UK. Email: m.cooper@open.ac.uk
} 
disabilities interact with the computer using methods other than the conventional monitor, keyboard and mouse; some require special tools, usually referred to as 'assistive technology'; and some need the way content is presented to them by the computer to be appropriate to their needs (e.g. in terms of font sizes and/or colour contrast). There are well-established principles in how to promote accessibility in software design and electronic content (IMS Global Learning Consortium, 2002; Cooper, 2003). These promote compatibility with assistive technology and ensure that different ways of interacting with the computer can be accommodated.

It is pertinent to pause at this point and reflect on what we are seeking to promote in addressing the accessibility agenda in e-learning; that is, access to what? Fundamentally it is the teaching and learning offered that needs to be made accessible. However, if a disabled student is to fully participate in their course and university life, accessibility must include all aspects of the interaction between the student and the institution. This includes registration, teaching and learning, examinations and other forms of assessment, study support, pastoral care and community building. Then we should consider the question: access for whom? Essentially the answer is 'access for all students', including students and potential students with a disability; covering all types of disability - physical, sensory, specific learning disabilities including dyslexia, mental health and hidden disabilities such as chronic fatigue, and so on. If you fail to address issues of accessibility, you will exclude or disadvantage significant numbers of people:

- Disabled people represent about $10-15 \%$ of the general population.

- Among OU students, 5.5\% declare a disability.

- Recent Microsoft-commissioned market research (Microsoft, 2004) shows that $57 \%$ of working-age computer users are likely to benefit from accessible technology (where accessible technology is understood as technical responses to promote access for disabled people to computer hardware and software).

Good design for disabled people is good design for all. Considering the needs of disabled students facilitates reflection on the interactions that support the learning objectives, and addressing the accessibility agenda promotes usability for all.

In its work developing international standards for metadata that enable automatic systems-based approaches to accessibility in e-learning, the IMS Accessibility Working Group ${ }^{1}$ (now IMS AccSIG) re-defined disability in the e-learning context as a mismatch between the education offered and the needs and preferences of the learner (IMS Global Learning Consortium, 2004). Disability is therefore not a personal trait, but an artefact of the relationship between the learner and the learning environment or education delivery. Accessibility, given this re-definition, is the ability of the learning environment to adjust to the needs of all learners. Accessibility is determined by the flexibility of the e-learning system (with respect to presentation, control methods, access modality and learner support) and the availability of adequate alternative-butequivalent content and activities. The needs and preferences of a user may arise from the context or environment the user is in, the tools available (e.g. assistive technologies such as Braille devices, voice recognition systems, or alternative keyboards, etc.), 
their background or a disability in the traditional sense. Metadata-based systems responses to the accessibility agenda is beyond the scope of this paper. For those who are interested, please see the IMS AccessForAll Overview Document (IMS Global Consortium, 2004).

\section{The UK legislative context}

Many countries are introducing legislation, making it illegal to discriminate against disabled people in education. In the United Kingdom the key legislation is the Special Educational Needs and Disability Act 2001 (HMSO, 2001). This amends the 1995 Disability Discrimination Act (DDA) (HMSO, 1995) and now constitutes DDA Part 4. This Act legislates that education providers must not treat a disabled person less favourably for any reason that relates to the person's disability. Furthermore, the education provider is required to make reasonable adjustments to enable a disabled person to participate in its courses. Access to the online elements of its courses is an important area where, by considering the needs of disabled students, discrimination can be prevented. Furthermore, it is where, if necessary, reasonable adjustments can readily be made to meet the diverse needs of students with disabilities. An important feature of the Act is that the needs of disabled students need to be anticipated and that it is therefore not sufficient for an educational establishment just to attempt to deal with the needs of a disabled student as they arise. This is important because where this has been past practice, the needs of disabled students have often been poorly met, because of lack of forward thinking. Mason and Casserle (2005) offer a useful review of key DDA and web accessibility cases (although not specifically related to education).

Reasonable adjustments. The term 'reasonable adjustment' is used widely in the DDA Part 4, and it begs the question 'what is reasonable?' This is a moot point and one that almost has to be considered on a case-by-case basis. However, the act is supported by a Code of Practice (Disability Rights Commission, 2004) that gives examples of the types of activity that should be considered and may require adjustment. Reasonable adjustments should be made to make all learning activities accessible to disabled students. This includes all learning materials: paper-based, web-based or computer-based, videos, audio, and so on. If this is not possible for some reason, alternative learning activities should be provided. Returning to the question 'what is reasonable?', the Code of Practice has a section offering guidance here. Some of the factors that might be taken into account when considering what is reasonable include the following:

- the need to maintain academic and other prescribed standards;

- the financial resources available to the responsible body;

- grants or loans likely to be available to disabled students (and only disabled students) for the purpose of enabling them to receive student services, such as Disabled Students' Allowances; 
- the cost of taking a particular step;

- the extent to which it is practicable to take a particular step;

- the extent to which aids or services will otherwise be provided to disabled people or students;

- health and safety requirements; and

- the relevant interests of other people including other students.

It is up to each higher educational establishment to determine how it responds to this legislation across its institution. Key issues in this response are whose responsibility is accessibility and how are decisions about reasonable adjustments made and recorded.

\section{The Open University context}

The OU is Europe's largest educational establishment, with the vast majority of its courses being delivered predominantly at a distance. The OU has invested $£ 30$ million in e-learning over the seven-year period to the end of 2004. Investment continues with a $£ 5$ million Virtual Learning Environment project and further substantial investment in an Enterprise Content Management System is ongoing. It seeks to pay appropriate regard to accessibility issues in these developments with two specific goals:

- Leveraging the potential of these technologies/systems to improve the effectiveness and efficiency with which the university can meet the needs of its disabled students.

- Ensuring that these developments do not introduce additional barriers to learning for students with disabilities.

The OU has a commitment to:

- widening access to higher education by helping students to overcome barriers to their study;

- providing high-quality, interactive educational materials that meet students' needs; and

- operating within the over-arching mission of 'openness to all'.

The OU's extensive experience in production and delivery of large-scale e-learning is demonstrated by the following statistics:

- About 200,000 OU students and their tutors (8000) have been given an account on the university's email and computer conferencing system. This conferencing system is used extensively in the delivery of most courses and is the basis of much of the contact between students, their peers and their tutor between the typically monthly face-to-face tutorial that is part of the delivery of many courses.

- 106,000 OU assignments annually (one in eight of all assignments) are submitted electronically.

- About 17 of the university's 400 courses are wholly 'online'. Another 190 require the student to have online access (for delivery of course materials, study support, etc.); the remaining courses provide online services for the students to access if they wish. 
The OU currently has about 10,000 disabled students, approximately one-half of whom receive some particular support from the university to enable them to participate in their studies. The university is committed to making its online educational content and student services accessible to disabled students, but the scale of this presents a challenge.

\section{The OU experience of making online materials accessible}

The OU experience of making online materials accessible raises important questions and highlights pertinent issues:

- Who is responsible for accessibility?

- What are we seeking to make accessible?

- What educators should know about accessibility.

These issues will now be addressed in turn.

\section{Whose responsibility?}

The issue of responsibility for accessibility is often helpfully thought of in the same way that responsibility in health and safety legislation is considered. The ultimate responsibility lies with the governing body of the institution. This responsibility is devolved by them to specific named individuals or posts across the organisation; however, all employees have a responsibility for health and safety. So in the case of accessibility to online learning, all involved in its conception, implementation and delivery have a responsibility for its accessibility. However, specific responsibilities should be given to key people. Within the OU, the teams that develop each course (and ultimately the Deans of Faculties) are responsible for the accessibility of their courses. How this responsibility is handled within each course team is left to them to organise. It is recommended that they appoint one of their members to take specific responsibility for ensuring that accessibility issues are properly addressed. This person may or may not be the course team chair. All course team decisions on accessibility and reasonable adjustments should be documented, and a protocol has been established for doing this within the formal course development process. It is important to record the rationale for these decisions, both as part of the internal management of course development and because it is these decisions that could be subject to legal challenge under DDA Part 4. Furthermore, it is important to inform disabled students ahead of their enrolment on a course of any particular accessibility issues that elements of the course may present them and where they may be offered an alternative activity.

It is also important to clearly establish the division of responsibilities between the educators devising the course and the developers implementing its software and webbased components.

At the OU it has been argued that accessibility is intrinsically linked to the learning objectives; the author would assert this is the case in all e-learning irrespective of 
institutional context (see the following section). Hence, the approach taken at the OU is that it is the educators' responsibility to specify the accessibility criteria but the developers' responsibility to determine how these are met in the technology they employ. In reality these responsibilities are acted out in iterative discussions between educators and developers.

There are several specialist units within the OU that support different aspects of the university's work in meeting the needs of disabled students. These include the Office for Students with Disabilities, the Curriculum Access team within Disabled Student Services (DSS-CA), and the Accessibility in Educational Media (AEM) team within the Institute of Educational Technology, which the author heads.

Every student receives support from a Regional Office and has a tutor, now known as an Associate Lecturer. Associate Lecturers and Regional Disability Advisors have an important role to play in supporting disabled students and mediating between the student and the rest of the OU when an adjustment is required that has not been anticipated. Students themselves also have responsibilities including making their needs known.

It is important to note that the primary responsibility for accessibility in courses is not devolved to these specialist units, but remains with the teams developing the courses. However these units support the roles of the course teams in different ways. The Curriculum Access team within Disabled Student Services and the AEM have collaborated in delivering an extensive staff development programme designed to ensure that all faculties and their staff realise their responsibilities in response to DDA Part 4. They also have a significant internal consultancy role with course teams and the developers working with them. This covers the accessibility issues raised by different elements in their courses, including their web presence and other use of computers in activities central to their course. This role includes validating that accessibility approaches adopted have in fact successfully met the needs of disabled students. Thus course teams and their developers can call upon specialist support at all stages of the development of online components: conceptualisation and specification; evaluation of early prototypes and evaluation of final developments before they are released.

\section{What are we seeking to make accessible?}

So often in accessibility considerations of educational websites or software the focus is on how best to make a particular element technically accessible to disabled students. However, the author maintains that educators need to stand back from these considerations and remember that, fundamentally, what we are seeking to make accessible is the learning. This may seem an obvious statement but it is often missed, and is key to deciding what is the most appropriate response to meet the needs of disabled students. Thus, fundamental to accessibility considerations in online education is having clearly established learning objectives. This is important through different degrees of granularity from the overall learning objectives for the course to the learning objectives for the individual activities being mediated online. By analogy, 
it is the case when considering the accessibility of any online service that it is the objectives of that service that must be referred to in determining the best way to make it accessible, and not in the first place the technology envisaged as being used to implement that service.

An important concept in accessibility is that of alternative presentation or equivalent activity. Often a decision has to be made as to whether accessibility is best achieved for a particular group of disabled students by presenting the same element in a different way (e.g. by using a detailed text description of a set of data instead of a graph for visually impaired students, or whether a totally different although educationally equivalent activity is more appropriate). It is the learning objectives that need to be referred to as the basis of such decisions.

An example from experience at the $\mathrm{OU}$ that illustrates this is on a programming course that uses a specific programming environment, which is inaccessible to some disabled students. If the learning objectives are to learn a particular programming language, students could use an alternative (equivalent) programming environment that is accessible. However, this would not be appropriate if the objectives are to learn to use that specific programming environment. If the latter is the case, then a clear rationale must be agreed as to why this particular programming environment is so important to the objectives of the course. A further example from an assessment issue on an OU course is where a video is used showing a conversation between a social worker and a child. If the learning objective is to appreciate that non-verbal communication takes place, and the assessment requires the student to describe the body language, then an alternative activity and assessment should be devised for blind students.

Situations where visual or auditory discernment form part of the learning objective present particular challenges when deciding how best to make them accessible to those with a significant impairment in the relevant sense. The standard approach of including an equivalent text description or transcription is often not appropriate here. This is because it is difficult to construct these textual equivalents in such a way that they still meet the sensory discernment aspects of the learning objectives. Basically, the issue is how to construct a description that does not simply 'give the answer away'. This can make it difficult to create a description that is effective in promoting the learning of the skill one is seeking to develop in the student. In such cases, how the learning objectives of this particular activity relate to the overall learning objectives of the course should be considered. Often the appropriate response is to develop an alternative activity that has an equivalent weight of contribution to these overall objectives in the same basic area as problematic activity but does not include the sensory discernment objectives. However, it must be accepted that there are fundamental limits to accessibility.

\section{What educators should know about accessibility}

All educators need not become accessibility experts, although some might do this and support colleagues in this area. However, all educators need to have an appreciation 
of the issues and an overview of how disabled students may select to make effective use of the computer. This general level of knowledge about the area is important in avoiding the 'assumption of limitation'. This can be illustrated by the comments that educators are sometime heard to make, of the type: 'I don't think a blind person could possibly do this'. Sometimes they may think this because they have little knowledge of coping strategies adopted by blind people or technological or human support available to them. A blind person might readily be able to do the task in question, say with the aid of their assistive technology, if the appropriate response is made in the devising of that task.

This general awareness of accessibility is also important in ensuring that accessibility issues are addressed at the right time, at the conceptualisation and specification stage of a component in online learning, not just discovered once the learning object has been developed. It is a too frequent frustration to those working in accessibility that they are repeatedly presented with situations where they are asked to comment on the accessibility of an online component once it is developed. Often widespread accessibility could have been readily achieved if it had been considered at the outset, but now only limited accessibility can be achieved because of time, technical or cost constraints. Meeting the accessibility agenda does incur costs but these costs are significantly lower if accessibility is considered from the outset rather than looking for a fix after the majority of the development work has been done. By giving all educators who might originate or specify online course components a general awareness of accessibility, they can be trained to at least ask the right questions about accessibility at the early stages even if they do not know the answers.

A brief overview of the accessibility information that it has been judged as important for educators at the OU to know is now presented. This is considered from both ends of the problem; firstly how disabled people use a computer and what assistive technology they may elect to use; and then what response is required by those developing online learning components to ensure it is compatible with the way that disabled students may be seeking to access these.

Assistive technology. Virtually all disabled people can be enabled to make effective use of a computer. Some disabled students use accessibility features provided by the operating systems of the computer and/or specialist software or hardware to facilitate their use of the computer. These software or hardware tools are often referred to collectively as 'assistive technology'. ${ }^{2}$ If it is to be accessible to disabled students, any software or educational content mediated by the computer has to be developed so that it is compatible with these tools. It is important that all educators have an overview of how disabled students may use a computer and the implications of this for any software or web content they commission or develop.

The sort of level of detail most educators would need to know about assistive technology can be contained within a two-hour to three-hour staff development session. Experience at the OU has shown that such sessions have far more impact if different examples of assistive technology can be effectively demonstrated. There is a further 
issue that an educational institution needs to consider, and that is how students are supported in selecting and being trained in the use of the most appropriate assistive technology to support their studies. This is usually the domain of student support services or IT support staff who may call on services of Access or Assessment Centres. ${ }^{3}$ The OU has established its own Access Centre in Milton Keynes, has a mobile facility known as the Access Bus, and uses the services of other Access Centres where this is more appropriate to the student's location.

It is generally unhelpful to consider medical classifications of disability when seeking to identify the means of enabling people with disabilities to make efficient use of the computer. It is preferable to consider the abilities, and disabilities, of the individual with respect to what they need to do to make most effective use of the computer; in other words, to take a functional approach. The functions to be considered fall into two broad categories:

1. How the person may best input commands and information into the computer (here most computer users use the keyboard and mouse).

2. How the person receives the output from the computer (for most computer users this will generally be the monitor, but also includes loudspeakers and printers).

Accessible online content. There are extensive guidelines and software tools to support developers in producing accessible web content and other software that might be presented online. It is probably sufficient for educators to know that these resources exist but an understanding of the underlying accessibility principles will help them in their role and in managing the balance of responsibilities for accessibility between the commissioning educator and the developer.

The World Wide Web Consortium creates web standards. Under its Web Accessibility Initiative (WAI) it has drawn up extensive guidelines for creating webpages that are accessible to many people with a disability. It should be noted that these are guidelines to presenting information in an accessible way on the Web, and further resources may be needed when seeking to address some of the accessibility issues in interactive educational software. There are, for example, specific accessibility guidelines for particular programming languages that may be used to implement educational software (e.g. JAVA ${ }^{4}$ ).

The WAI guidelines, usually referred to as Web Content Accessibility Guidelines, can certainly at first sight appear complex and there are issues about how to best support developers in using them, but these are beyond the scope of this paper. There are 14 guidelines, each of which is associated with one or more checkpoints describing how to apply that guideline to particular features in webpages (WAI, 1999). Each checkpoint is assigned one of three 'priority' levels reflecting the impact that not following it will have on accessibility. Levels of conformance are then specified against these priorities. It is recommended that an educational website seeking to meet the needs of disabled students, and its obligations under DDA Part 4, should aim for 'Double-A' conformance, which means meeting all priority one and priority two checkpoints. This is in line with what is generally deemed to be accessible in various 
contexts across Europe. It should be noted, however, that it is perfectly possible for an e-learning website to be technically accessible (i.e. to meet all priority one and priority two checkpoints), but not to be able to facilitate the achieving of its learning objectives for some disabled users. Technical accessibility needs to be considered alongside usability and pedagogy in determining whether the learning objectives of a particular e-learning resource can be accessed by all learners.

Most websites and webpages are produced using authoring tools rather than 'hand crafting' hypertext mark-up (e.g. HTML). There is a high degree of variability in how readily these tools support authoring in a way that conforms to the accessibility guidelines. However, in response to US legislation, most of the major suppliers of such tools are seeking to address this in recent and planned releases.

\section{Underlying principles of software accessibility}

A summary of the main accessibility principles that the author believes staff in higher education need to know is presented here. It is recommended that all educators are cognisant of these to enable them to effectively take on their responsibilities for accessibility in the design of web and software course components.

- Allow for user customisation. Many different disabled people, including those with a visual impairment and dyslexia, find online content can be made more readable if they are able to choose particular font styles and sizes and use different background and foreground colours. Because of the wide diversity in what different people would select as their optimally readable configuration, this is best addressed by allowing them to configure these. This is usually most readily done by enabling the webpages or software to inherit user set parameters from the browser or computer operating system.

- Provide equivalent visual and auditory content and interface elements. Text is the most readily accessible form of online content. It can be rendered into synthetic speech by screen readers and configured for different presentation. Text descriptions should be provided for all images, graphics and video content, transcriptions provided of auditory content, and text labelling of interface elements included.

- Provide compatibility with assistive technologies. This simple statement hides a multitude of technical issues but, by following set web or software standards, the opportunities for this being adequately addressed are maximised as the assistive technologies are to a large part developed with these same standards in mind.

- Allow access to all functionality from the keyboard alone. Many disabled people are unable to or prefer not to use a mouse. This includes blind people and those with some physical disabilities. By ensuring that software can be fully used without a mouse, the needs of these users are met-but also generally more efficient interaction with the software is offered to all users.

- Provide context and orientation information. It is important to consider the accessibility issues of navigating around the content as well as the content itself. This is an often neglected area. Support should be provided for efficient navigation by 
informing the user of where they are, taking into account that some users may be using screen readers or other assistive technologies. This is another case where thinking about the needs of disabled users often yields benefits for all users by promoting usability generally.

\section{Conclusion}

Legislation now directs that online learning should be made accessible to disabled students, and most educational establishments would aspire to this from their own ethos. However, to achieve this requires cultural change across the organisation. I have reflected on the process of promoting this cultural change within the OU. The importance of being clear about roles and responsibilities in promoting accessibility has been stated and the centrality of the educators' role in this has been argued. They of course need to be provided with the necessary expert support to enable them to take on this responsibility.

The fundamental importance of the learning objectives in establishing accessibility criteria and in identifying and making adjustments to online course components to meet the needs of disabled students has also been highlighted. This is a key point. It is from this that the centrality of the educators' role follows. The knowledge that educators need to know about accessibility issues to enable them to perform this role has been outlined. This has been the basis of the staff and professional development programme in response to DDA Part 4, enacted at the OU across all its faculties, and such an approach would be commended to other institutions.

\section{Acknowledgements}

The author would like to thank all within the OU, and elsewhere, who have informed his thinking on these issues over the years. In the preparation of this paper, the author would particularly like to thank Mary Taylor, a colleague in the AEM team in the Institution of Educational Technology at the OU, who proof-read the text and made suggestions for its improvement, and Peter Wilson of the Policy Development Group, who supplied the current data about the status of e-learning in the OU.

\section{Notes}

1. IMS develops and promotes the adoption of open technical specifications for interoperable learning technology. For detailed information on the work of the Accessibility SIG see: http:// www.imsglobal.org/accessibility/index.cfm

2. See BECTA factsheets on 'Using ICT in special needs and inclusive education' for more detailed description of the use of assistive technologies within education: http:// www.becta.org.uk/leas/display.cfm?section=13_1\#sn. See also AbilityNet factsheets including 'Technologies and approaches, services and organisations, which can help anyone who has a special IT requirement' for more detailed description and overview of assistive technologies: http://www.abilitynet.org.uk/content/factsheets/Factsheets-list.htm 


\section{M. Cooper}

3. Access or Assessment Centres are usually, but not always, based in colleges of further or higher education. They provide assessments and training services for disabled students who are able to apply for the Disabled Students Allowances funded by the DFES. Most centres belong to the National Network of Assessment Centres (http://www.nnac.org./)

4. Accessibility guidelines, tutorials and tools for developers working in JAVA have been made available by SUN Microsystems (http://www.sun.com/access/developers/index.html).

\section{Other useful resources}

Accessibility in Educational Media (AEM) and other OU resources:

- AEM's WWW home page: http://iet.open.ac.uk/aem

- AEM Knowledge Network home/links page: http://kn.open.ac.uk/public/ index.cfm?wpid=954

- Accessibility Primer: http://kn.open.ac.uk/public/index.cfm?wpid=2488

- OU services for disabled students: http:/www.open.ac.uk/disability/pages/ common/index.php

- Guidelines for describing visual material: http://kn.open.ac.uk/public/ index.cfm?wpid=2709

- OU software/web developers accessibility guidelines: http://kn.open.ac.uk/public/ index.cfm?wpid=2408 and http://kn.open.ac.uk/public/index.cfm?wpid=2451

WAI Content Guidelines for creating accessible webpages (WCAG) v1.0:

- Content Guidelines: http://www.w3.org/TR/WAI-WEBCONTENT/

- Techniques: http://www.w3.org/TR/WAI-WEBCONTENT-TECHS/

- Checklists: http://www.w3.org/TR/WAI-WEBCONTENT/full-checklist.html

Accessibility validators:

- Bobby: http://webxact.watchfire.com/

- Prompt: http://www.aprompt.ca/

\section{References}

Cooper, M. (2003) Communications and information technology (C\&IT) for disabled students, in: S. Powell (Ed.) Special teaching in higher education-successful strategies for access and inclusion (London, Kogan Page).

Disability Rights Commission (2004) Code of Practice for providers of post 16 education and related services-DDA 1995: Part 4. Available online at: http://www.drc.org.uk/thelaw/practice.asp (accessed 11 January 2006).

HMSO (1995) Disability Discrimination Act 1995. Available online at: http://www.legislation.hmso.gov.uk/acts/acts 1995/1995050.htm (accessed 14 November 2005).

HMSO (2001) Special Educational Needs and Disability Act 2001 (SENDA). Available online at: http://www.hmso.gov.uk/acts/acts2001/20010010.htm (accessed 14 November 2005).

IMS Global Learning Consortium (2002) Guidelines for developing accessible learning applications. Available online at: http://www.imsglobal.org/accessibility/accv1p0/imsacc_guidev1p0.html (accessed 14 November 2005).

IMS Global Learning Consortium (2004) AccessForAll Meta-data Overview Version 1.0 Final Specification, 2004. Available online at: http://www.imsglobal.org/accessibility/accmdv1p0/ imsaccmd_oviewv1p0.html (accessed 14 November 2005). 
Mason, S. \& Casserle, C. (2005) Web site design and the Disability Discrimination, Act 1995, Computer Law \& Security Report, 21, 298-309.

Microsoft (2004) The wide range of abilities and its impact on computer technology. Available online at: http://download.microsoft.com/download/0/1/f/01f506eb-2d1e-42a6-bc7b-1f33d25fd40f/ ResearchReport.doc (accessed 14 November 2005).

WAI (1999) Web content accessibility guidelines 1.0, W3C recommendation 5 May 1999. Available online at: http://www.w3.org/TR/WCAG10/ (accessed 18 May 2005). 
